\title{
Preliminary evaluation of resorcinol-formaldehyde carbon gels for water pollutants removal
}

\author{
Muhammad Abbas Ahmad Zainia, be Seiichiro Yoshidac, \\ Takeshi Moric, Shin R. Mukaic \\ ${ }^{a}$ Centre of Lipids Engineering $\mathcal{\Xi}^{2}$ Applied Research, Ibnu-Sina Institute for Scientific E Industrial Research, \\ Universiti Teknologi Malaysia, 81310 UTM Johor Bahru, Johor, Malaysia \\ ${ }^{b}$ Faculty of Chemical Eं Energy Engineering, Universiti Teknologi Malaysia, \\ 81310 UTM Johor Bahru, Johor, Malaysia \\ ${ }^{c}$ Division of Chemical Process Engineering, Graduate School of Engineering, Hokkaido University, \\ N13W8 Kita-ku, Sapporo 060-8628, Japan \\ abbas@cheme.utm.my
}

\begin{abstract}
The present work was aimed to evaluate the suitability of resorcinol-formaldehyde carbon gels as adsorbent for water pollutants removal. The carbon gels were characterized using $\mathrm{N}_{2}$ adsorption-desorption isotherm for specific surface area, and Fourier transform infrared (FTIR) for surface functional groups. Methylene blue and cesium were employed as model water pollutants. Results show that the un-oxidized carbon gel, despite its lower specific surface area $\left(333 \mathrm{~m}^{2} / \mathrm{g}\right)$ displayed a $118 \mathrm{mg} / \mathrm{g}$ removal of methylene blue, that is higher than $35 \mathrm{mg} / \mathrm{g}$ by the oxidized carbon gel $\left(418 \mathrm{~m}^{2} / \mathrm{g}\right)$. The evaluation of adsorption kinetics revealed a lower pseudo-first order rate constant of $0.088 \mathrm{~h}^{-1}$ for $10 \mathrm{mg} / \mathrm{L}$ methylene blue adsorption. A positive effect of surface oxidation was demonstrated for cesium adsorption. On molar basis, however, the oxidized carbon gel exhibits a selective removal towards methylene blue compared to cesium. Carbon gel is a promising candidate for water pollutants removal, and further treatment needs to be sought to boost its performance.
\end{abstract}

Keywords: Adsorption, carbon gel, cesium, methylene blue, surface oxidation

\section{Introduction}

There is an increasing concern over the release of organic and inorganic pollutants into the water bodies. The water contaminants have a damaging effect not only to the aquatic ecosystem and the living creatures therein, but also to human who rely on water and its resources for daily life. Therefore, the effluent requires necessary treatment before it damages the water resources. Among the broad treatment strategies, adsorption has emerged as the widely tested method in wastewater treatment. It is a process whereby the contaminants (solutes) are adhered to the surface of solid adsorbent through various mechanisms such as pore filling, $\pi-\pi$ interaction, ion-exchange and formation of chelate/complex [1]. In real industrial process that deals with huge volume of wastewater, adsorption through continuous setting is more preferable because of easy and simple operation, minimum manufacturing costs and less space needed. However, the commercial adsorbents produced nowadays are in granular and powder forms that are unsuitable for continuous process. Despite the high specific surface area and rich in surface chemistry for satisfactory removal performance, the column operation employing adsorbent with tiny particles is likely to suffer in escalating pressure drop due to hydraulic resistance [2]. Consequently, this may result in high operating costs and poor column performance.

A possible solution to this setback is a packingtype adsorbent called carbon gel. Carbon gel is produced through polymerization of resorcinol and formaldehyde in the presence of solvent (water) and basic catalyst (sodium carbonate) [3]. The mesoporous carbon network is established via the aggregation of nanometer-sized colloidal particles. The voids formed between the nanoparticles formed a hierarchical pore system of mainly mesopores, and some micropores and macropores [4]. Carbon gel is a porous material with high carbon density that can be mould into desired size, and tailored for specific applications such as carbon electrodes for energy storage, catalysts for chemical synthesis, and adsorbents for chemical separation and environmental protection $[4,5]$. Because of these unique characteristics, carbon gel is seen as a promising candidate to overcome the resistance to flow and promote a short path for effective contact between the solute and solid surface in continuous mode of adsorption [2].

To date, the use of carbon gel as adsorbent for pollutants removal especially in continuous mode is 
not widely available in literature. As a preliminary assessment, the present study is embarked to evaluate the removal of some pollutants from water by resorcinol-formaldehyde carbon gel (RC). The batch mode was used as initial step to establish insight into the application of column/continuous system. Two model pollutants, namely methylene blue $\left(\mathrm{MB}^{+}\right.$, effective radius $=0.62 \mathrm{~nm})$ and cesium $\left(\mathrm{Cs}^{+}\right.$, ionic radius $=0.174 \mathrm{~nm}$, hydrated radius $=0.228 \mathrm{~nm})$ were used to investigate the performance of RC. Attempt has also been made to modify the RC surface by oxidation using $\mathrm{HNO}_{3}$. The adsorbents were characterized and the results of batch adsorption were discussed.

\section{Materials and methods}

\subsection{Materials}

Formaldehyde $(\mathrm{HCHO}, \mathrm{mw}=30.03 \mathrm{~g} / \mathrm{mol}$, $37 \mathrm{w} / \mathrm{w} \%$ in water $)$, resorcinol $\left(\mathrm{C}_{6} \mathrm{H}_{6} \mathrm{O}_{2}, \mathrm{mw}=\right.$ $=110.11 \mathrm{~g} / \mathrm{mol}$, assay $99 \%)$, sodium carbonate $\left(\mathrm{Na}_{2} \mathrm{CO}_{3}, \mathrm{mw}=105.99 \mathrm{~g} / \mathrm{mol}\right.$, assay $\left.99.5 \%\right)$, tertbutyl alcohol $\left(\left(\mathrm{CH}_{3}\right)_{3} \mathrm{COH}, \mathrm{mw}=74.12 \mathrm{~g} / \mathrm{mol}\right.$, assay $99 \%)$, nitric acid $\left(\mathrm{HNO}_{3}, \mathrm{mw}=63.01\right.$, 65-66\%), methylene blue $\left(\mathrm{C}_{16} \mathrm{H}_{18} \mathrm{ClN}_{3} \mathrm{~S}\right.$, mw = $=319.85 \mathrm{~g} / \mathrm{mol}$, assay $99 \%$ ) and cesium chloride $(\mathrm{CsCl}, \mathrm{mw}=168.36$, assay $99 \%)$ were used in the preparation of $\mathrm{RC}$ and adsorption studies. The chemicals were obtained from Wako Pure Chemical Industries Ltd., and are of analytical reagents grade.

\subsection{Preparation and characterization of carbon gels}

Carbon gel was chemically synthesized using resorcinol, formaldehyde, sodium carbonate and water. Twenty-five grams of resorcinol and $24.1 \mathrm{mg}$ of sodium carbonate (catalyst) was added into a disposable cup containing $29.7 \mathrm{~g}$ of water, and the mixture was stirred to dissolve the solids. Then, $36.85 \mathrm{~g}$ of formaldehyde was added to the liquid mixture. The sample (resorcinol/catalyst $=1000 \mathrm{~mol} / \mathrm{mol}$ ) was stirred, poured into a mould, and allowed at $35^{\circ} \mathrm{C}$ for two days for gelation of sol solution [6]. After that, the mould was heated at $60{ }^{\circ} \mathrm{C}$ for three days for gel aging. Then, the sample was subjected to solvent exchange using tert-butyl alcohol (TBA) to remove excess water from the interior matrix. The solid gel was mixed with TBA in a capped bottle, and kept at $50{ }^{\circ} \mathrm{C}$ for three days. The solvent was replaced with the fresh one twice a day. Finally, the gel was oven-dried at $110{ }^{\circ} \mathrm{C}$ for two days.

The gel was ground and sieved to a size of $0.6 \mathrm{~mm}$. The carbonization of gel was carried out at $1000{ }^{\circ} \mathrm{C}$ for $4 \mathrm{~h}$ in a tubular furnace under $\mathrm{N}_{2}$ flow. The heating was ramped at $250{ }^{\circ} \mathrm{C} / \mathrm{h}$ and was hold at
$250{ }^{\circ} \mathrm{C}$ for $2 \mathrm{~h}$. The resultant material is resorcinolformaldehyde carbon gel, and was designated as RC. The oxidation of RC was carried out by mixing the sample with nitric acid $(65-66 \%)$ at $50{ }^{\circ} \mathrm{C}$ for $12 \mathrm{~h}$ [7]. The oxidized sample was washed with distilled water to a constant $\mathrm{pH}$, and designated as Ox-RC.

The adsorbents were characterized for specific surface area and pore volume and functional groups. The textural properties of RC samples were determined using a BelsorpII mini (BEL, Japan Inc.) at liquid nitrogen temperature of $77 \mathrm{~K}$. The SEM images and FTIR spectra were obtained using SU 1510 SEM (Hitachi) and $6100 \mathrm{HMO} \mathrm{FT/IR} \mathrm{(Jasco}$ Corp.), respectively.

\subsection{Batch adsorption studies}

Fifty milligrams of adsorbent was brought into intimate contact with $20 \mathrm{~mL}$ of model pollutants at varying initial concentrations: methylene blue $\left(\mathrm{MB}^{+}\right.$, 5 to $600 \mathrm{mg} / \mathrm{L})$; cesium $\left(\mathrm{Cs}^{+}, 2\right.$ to $\left.100 \mathrm{mg} / \mathrm{L}\right)$. The solution $\mathrm{pH}$ was not adjusted and the mixture was allowed to equilibrate for four days. The $\mathrm{pH}$ values were measured using a Horiba LAQUAact pH meter (Horiba Scientific). The residual concentration of $\mathrm{MB}^{+}$was measured using a UV-2400PC uv-vis spectrophotometer (Shimadzu) at a wavelength of $600 \mathrm{~nm}$, while that of $\mathrm{Cs}^{+}$using a CD-200 conductivity detector ion chromatography (Shodex).

\section{Results and discussion}

\subsection{Characteristics of carbon gels}

Table 1 displays the physical characteristics of RC and $\mathrm{Ox}-\mathrm{RC}$.

Tab. 1. Physical characteristics of carbon gels.

\begin{tabular}{lcc}
\hline & RC & Ox-RC \\
\hline Yield & 51.1 & 51.1 \\
$\mathrm{pH}$ & 6.7 & 4.6 \\
BET surface area $\left(\mathrm{m}^{2} / \mathrm{g}\right)$ & 333 & 418 \\
Total pore volume $\left(\mathrm{cm}^{3} / \mathrm{g}\right)$ & 0.59 & 0.63 \\
${ }^{\mathrm{a}}$ Micropore volume $\left(\mathrm{cm}^{3} / \mathrm{g}\right)$ & 0.0928 & 0.146 \\
Mesopore volume $\left(\mathrm{cm}^{3} / \mathrm{g}\right)$ & 0.497 & 0.483 \\
Mesopore content $(\%)$ & 84.3 & 76.8 \\
Average pore width $(\mathrm{nm})$ & 7.09 & 6.02 \\
\hline
\end{tabular}

a at $p / p_{o}=0.15$

Nearly $50 \%$ of resorcinol-formaldehyde gel (RF) mass is liberated during carbonization, while no change in mass was observed after surface modification with $\mathrm{HNO}_{3}$. Upon carbonization, RF is transformed into a structure of nanometer-sized, high density aggregates of carbon particles [6]. A lower 
$\mathrm{pH}$ of Ox-RC could be due to surface protonation and functionalization by acidic oxygen groups [7]. The BET surface area of Ox-RC is slightly improved with a small decrease in mesopore content after the oxidation procedure.

Figure 1 shows the $\mathrm{N}_{2}$ adsorption-desorption isotherms of RC and Ox-RC. According to the IUPAC classification, the isotherms may fall under Type IV with an $\mathrm{H} 4$ hysteresis [8]. A steep increase of volume adsorbed at low relative pressure, $p / p_{o}$ is an indication of microporous structure. The adsorption capacity gradually increased as $p / p_{o}$ increases, and forms a nearly overlapped hysteresis as $p / p_{0}$ approaching unity. The capillary condensation behaviour at high $p / p_{o}$ indicates that the samples are rich in mesopores (Table 1). Obviously, Ox-RC demonstrates a slightly higher $\mathrm{N}_{2}$ adsorption, thus a greater specific surface area compared to RC. Figure 2 shows the DollimoreHeal (DH) pore distribution of carbon gels. Both carbon gels display similar sharp peaks centred at $r_{p}=29.9 \mathrm{~nm}$ (pore diameter $=59.8 \mathrm{~nm}$ ). It implies that both carbon gels, $\mathrm{RC}$ and $\mathrm{Ox}-\mathrm{RC}$ are highly mesoporous with 84.3 and $76.8 \%$ mesopore content, respectively.

Figure 3 shows the SEM images of RC and Ox-RC. Cracks and crevices were observed on the surface of carbon gels. However, the debris particles are absence in Ox-RC. It is suggested that the use of $\mathrm{HNO}_{3}$ also assists in flushing the pore channels and so wiping out the deformed aggregates and debris, thus increasing the smooth access of pore volume and surface area of Ox-RC.

Figure 4 displays the FTIR spectra of carbon gels. Various functional groups were detected in resorcinolformaldehyde gel (RF). These include $\mathrm{O}-\mathrm{H}$ (moisture) stretching vibrations at $3791 \mathrm{~cm}^{-1}$, and $\mathrm{C}-\mathrm{C}$ stretching vibrations at $1874 \mathrm{~cm}^{-1}$. The peaks centred at 1506 and $1402 \mathrm{~cm}^{-1}$ could be assigned to $\mathrm{C}=\mathrm{C}$ (aromatic) stretching and $\mathrm{C}-\mathrm{H}$ (methylene, $\mathrm{CH}_{2}$ ) bending, respectively. However, the aforementioned peaks are mostly disappeared upon carbonization at $1000{ }^{\circ} \mathrm{C}$. Some shifted peaks with lower intensity were observed for RC and Ox-RC. It signifies the liberation of functional groups to form elementary

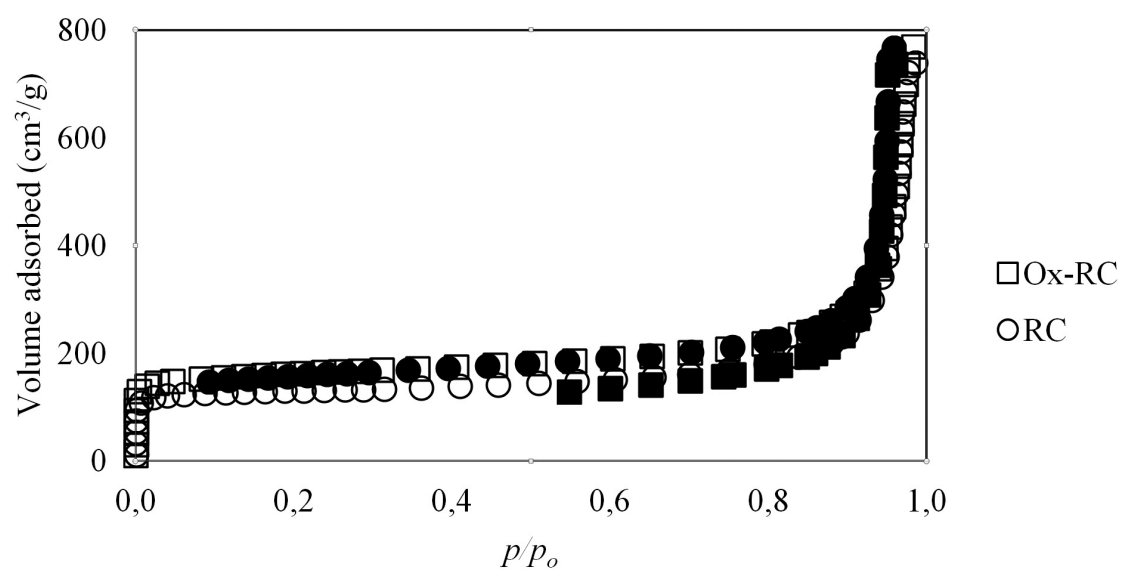

Fig. 1. $\mathrm{N}_{2}$ adsorption-desorption isotherms of carbon gels (open symbols: adsorption, closed symbols: desorption).

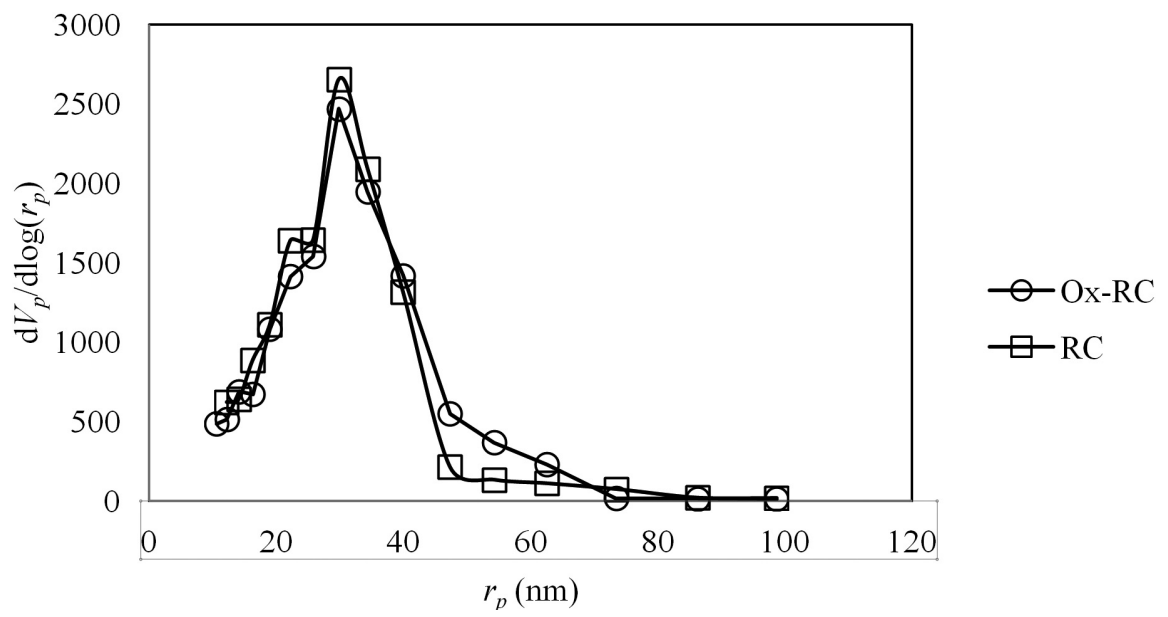

Fig. 2. Mesopore size distribution of carbon gels. 


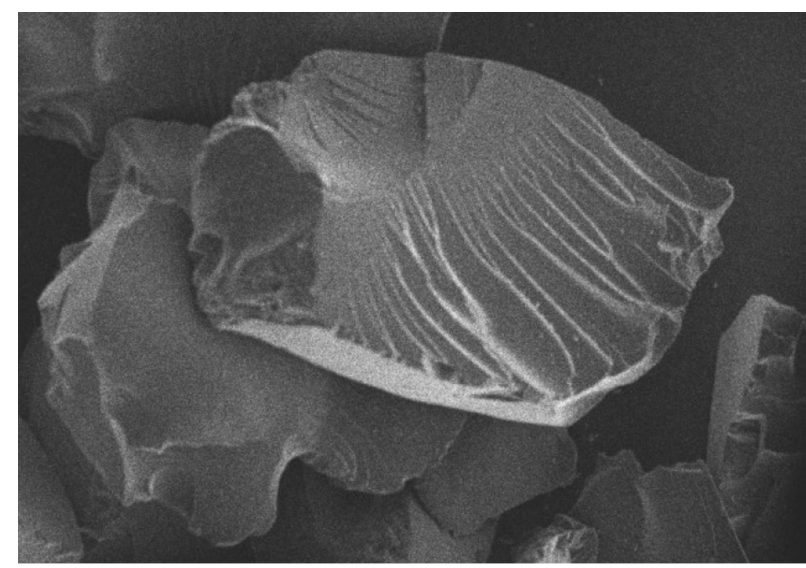

a)

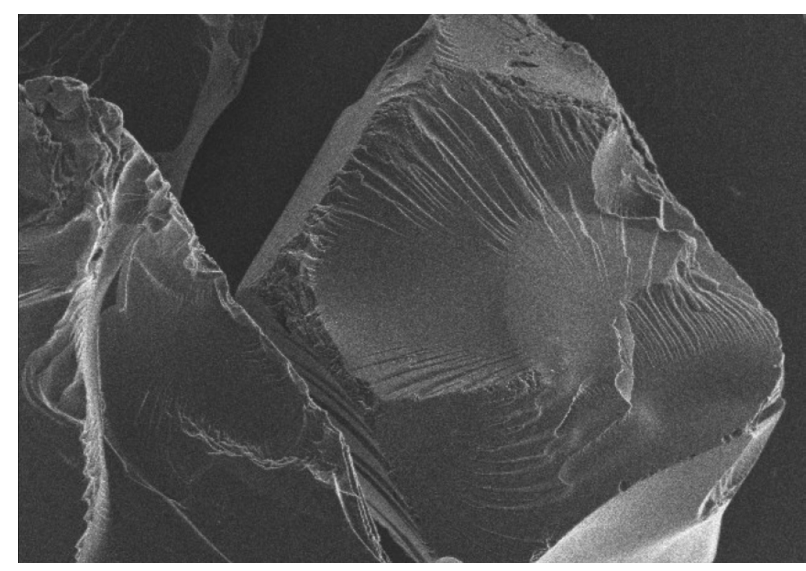

c)

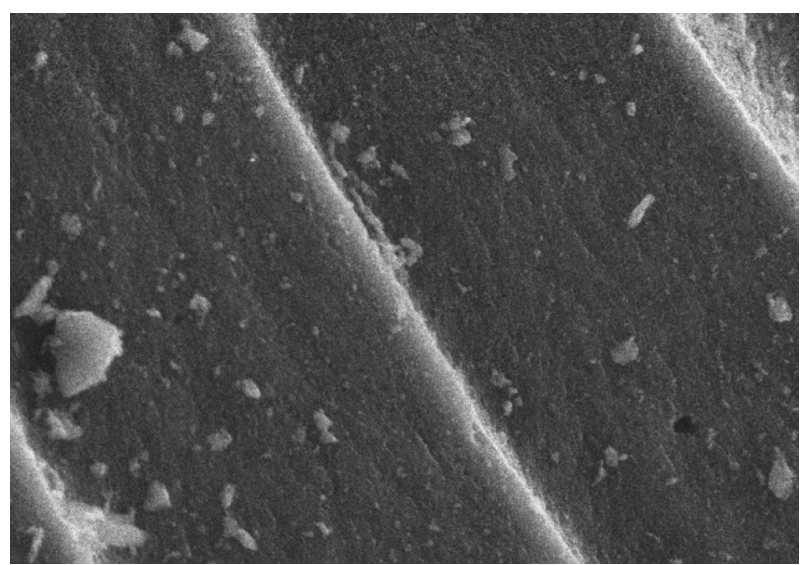

b)

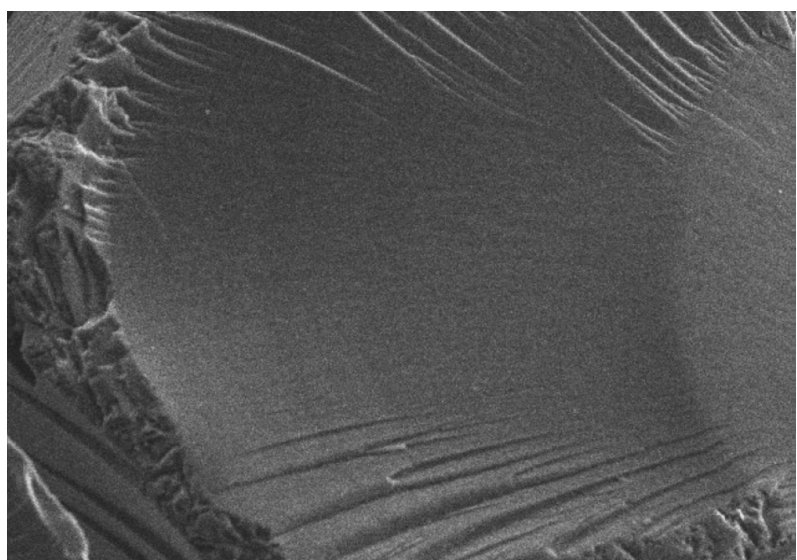

d)

Fig. 3. SEM images of carbon gels (RC: (a) and (b), Ox-RC: (c) and (d); (a) and (c) at $\times 50$ magnification, (b) at $\times 1000$ magnification, and (d) at $\times 100$ magnification)

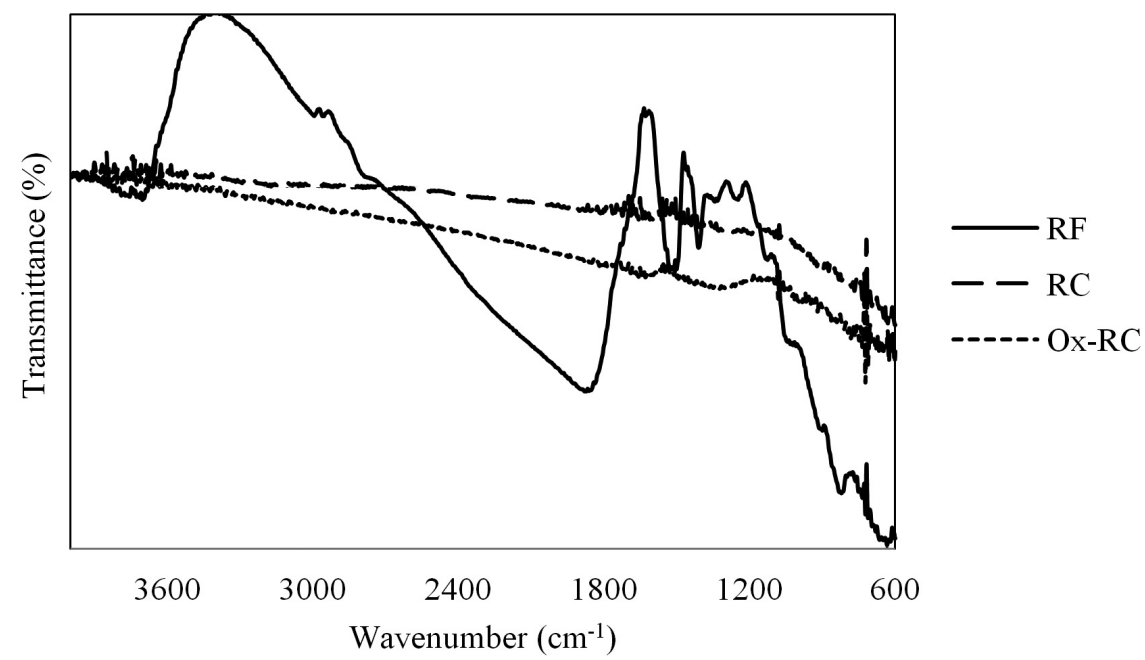

Fig. 4. FTIR spectra of resorcinol-formaldehyde gel and carbon gels.

carbon-rich (graphitic) structure of RC. In addition, the possible acidic functional groups in Ox-RC could not be detected probably due to strong absorption of infrared signals by rich carbon layer [9].

\subsection{Batch adsorption of methylene blue and cesium} Figure 5 shows the removal of methylene blue $\left(\mathrm{MB}^{+}\right)$by carbon gels.

Both carbon gels exhibit a strong adsorption in- 


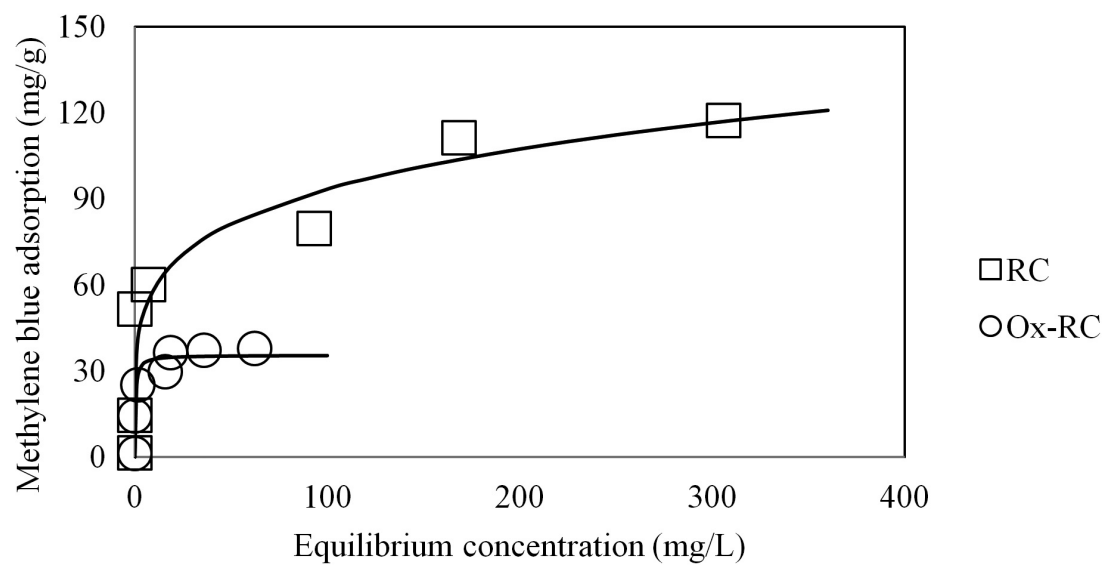

Fig. 5. Equilibrium adsorption of $\mathrm{MB}^{+}$by $\mathrm{RC}$ and $\mathrm{Ox}-\mathrm{RC}$ (adsorbent dosage $=0.05 \mathrm{~g}$, solution volume $=20 \mathrm{~mL}, \mathrm{MB}^{+}$concentration $=5$ to $600 \mathrm{mg} / \mathrm{L}$, contact time $=4$ days, lines for $\mathrm{RC}$ and

Ox-RC were predicted by Freundlich and Langmuir models, respectively).

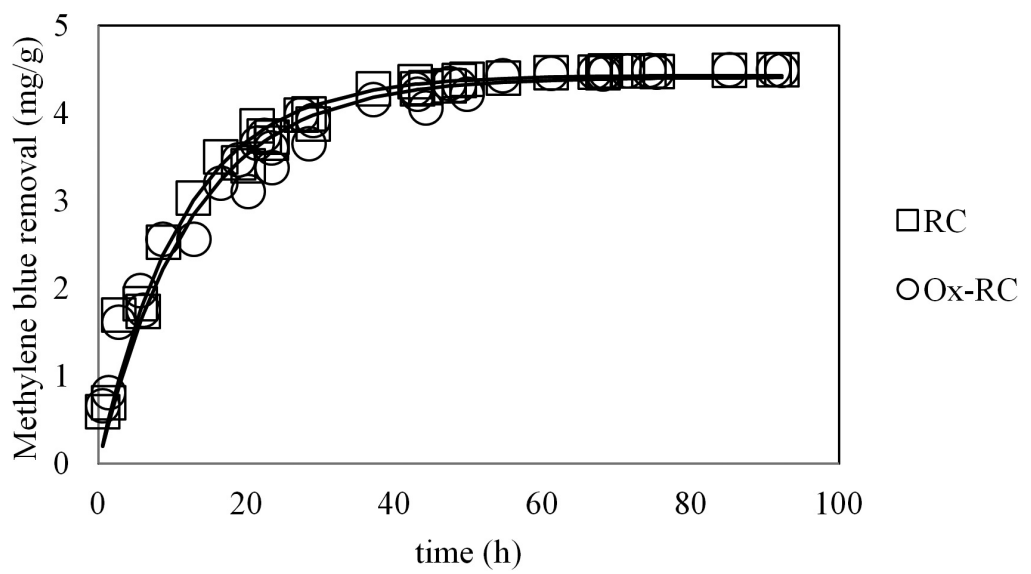

Fig. 6. Rate of $\mathrm{MB}^{+}$adsorption by $\mathrm{RC}$ and $\mathrm{Ox}-\mathrm{RC}$ (adsorbent dosage $=0.05 \mathrm{~g}$, solution volume $=20 \mathrm{~mL}$, $\mathrm{MB}^{+}$concentration $=10 \mathrm{mg} / \mathrm{L}$, lines were predicted by pseudo-first order kinetics model).

tensity (steep gradient) at low equilibrium concentration that signifies a favourable removal of methylene blue $\left(\mathrm{MB}^{+}\right)$. This could be associated with the mesoporosity of carbon gels [10]. As the equilibrium concentration increases, the removal of $\mathrm{MB}^{+}$by $\mathrm{Ox}-\mathrm{RC}$ began to levelled off at a capacity of $35 \mathrm{mg} / \mathrm{g}$, while $\mathrm{RC}$ continued to demonstrate a gradual increase with a recorded maximum uptake of $118 \mathrm{mg} / \mathrm{g}$. The removal performance of RC is similar to that of $\mathrm{ZnCl}_{2}$-activated carbon powder (surface area $=288 \mathrm{~m}^{2} / \mathrm{g}$, removal capacity $=154 \mathrm{mg} / \mathrm{g}$ ) [11], even though a greater methylene blue removal of $351 \mathrm{mg} / \mathrm{g}$ was reported using commercial activated carbon (surface area $=909 \mathrm{~m}^{2} / \mathrm{g}$ ) [10]. The model equations for RC and OX-RC are $q_{e}=36.9 C_{e}^{0.201}$ and $q_{e}=88.1 C_{e} /\left(1+2.48 C_{e}\right)$, respectively. Where $q_{e}$ $(\mathrm{mg} / \mathrm{g})$ is the adsorption of $\mathrm{MB}^{+}$by adsorbent at equilibrium concentration, $C_{e}(\mathrm{mg} / \mathrm{L})$ of dye solution. The fitting of adsorption data implies that the adsorption of $\mathrm{Ox}-\mathrm{RC}$ is monolayer on homogenous surface, while that of RC is heterogeneous in nature $[10,11]$. The surface modification (oxidation) of RC has resulted in a 3.4 times decrease of $\mathrm{MB}^{+}$removal. Although the adsorption of $\mathrm{MB}^{+}$may be driven by ion-exchange via dissociation of acidic oxygen groups, the protonated surface of Ox-RC may repel away the positively charged $\mathrm{MB}^{+}$molecules from the active sites, thus decreasing the removal capacity.

Figure 6 shows the rate of adsorption by carbon gels at $10 \mathrm{mg} / \mathrm{L}$, a concentration at which a strong adsorption intensity was displayed.

The rate curves are identical, whereby the equilibrium was attained only after three days of contact. The pseudo-first-order kinetics equations for RC and Ox-RC are $q_{t}=4.43\left(1-\mathrm{e}^{-0.088 t}\right)$ and $q_{t}=4.41\left(1-\mathrm{e}^{-0.080 t}\right)$, respectively. Where, $q_{t}(\mathrm{mg} / \mathrm{g})$ is the methyelene blue removal at time, $t(\mathrm{~h})$. The calculated values of rate constant are 0.088 and $0.080 \mathrm{~h}^{-1}$, respectively. From the viewpoint of adsorption kinetics, the values are undeniably small when compared to that of $\mathrm{ZnCl}_{2}$-activated carbon powder (rate constant $=49 \mathrm{~h}^{-1}$ for initial concentration of methyelene blue $=50 \mathrm{mg} / \mathrm{L}$, time to attain equilibrium $=45$ minutes) [11]. The rate of adsorp- 
tion becomes much slower for dye solution of high concentration, thus longer contact time would be needed to reach equilibrium. Hence, further treatment of carbon gel needs to be sought to boost the removal rate constant as the present finding may be viewed as less favourable for column operation.

The performance of carbon gels was compared using cesium $\left(\mathrm{Cs}^{+}\right)$. There is no appreciable removal of $\mathrm{Cs}^{+}$by $\mathrm{RC}$, and the average capacity for all concentrations studied is fluctuated at $0.12 \mathrm{mg} / \mathrm{g}$. On the other hand, a noticeable adsorption was observed by Ox-RC, where the capacity of $\mathrm{Cs}^{+}$increased with increasing concentration. The maximum removal capacity of $2.5 \mathrm{mg} / \mathrm{g}$ was recorded. It reveals a positive effect of using $\mathrm{HNO}_{3}$-treated carbon gel over the untreated one for $\mathrm{CS}^{+}$removal.

Figure 7 represents the removal of $\mathrm{MB}^{+}$and $\mathrm{Cs}^{+}$by Ox-RC in molar basis. It shows that the adsorption capacity of $\mathrm{MB}^{+}$prevailed over that of $\mathrm{Cs}^{+}$. In other words, $\mathrm{MB}^{+}$is more easily adsorbed than $\mathrm{Cs}^{+}$by OxRC. Figure 8 illustrates the relationship between the protons released by Ox-RC and the adsorption of model pollutants.

The lines through origin show a reasonably good fit between the adsorption data and amount of protons released. It implies the role of acidic oxygen functional groups in anchoring the positively charged pollutants via ion-exchange mechanism [12]. It was reported that the surface of $\mathrm{HNO}_{3}$-oxidized carbon is rich in carboxylic and phenolic groups [7, 12]. The proposed ion-exchange mechanism could be postulated as follows,

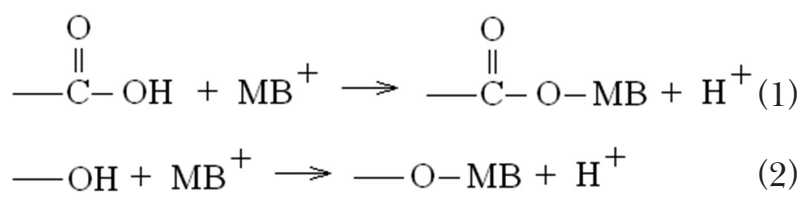

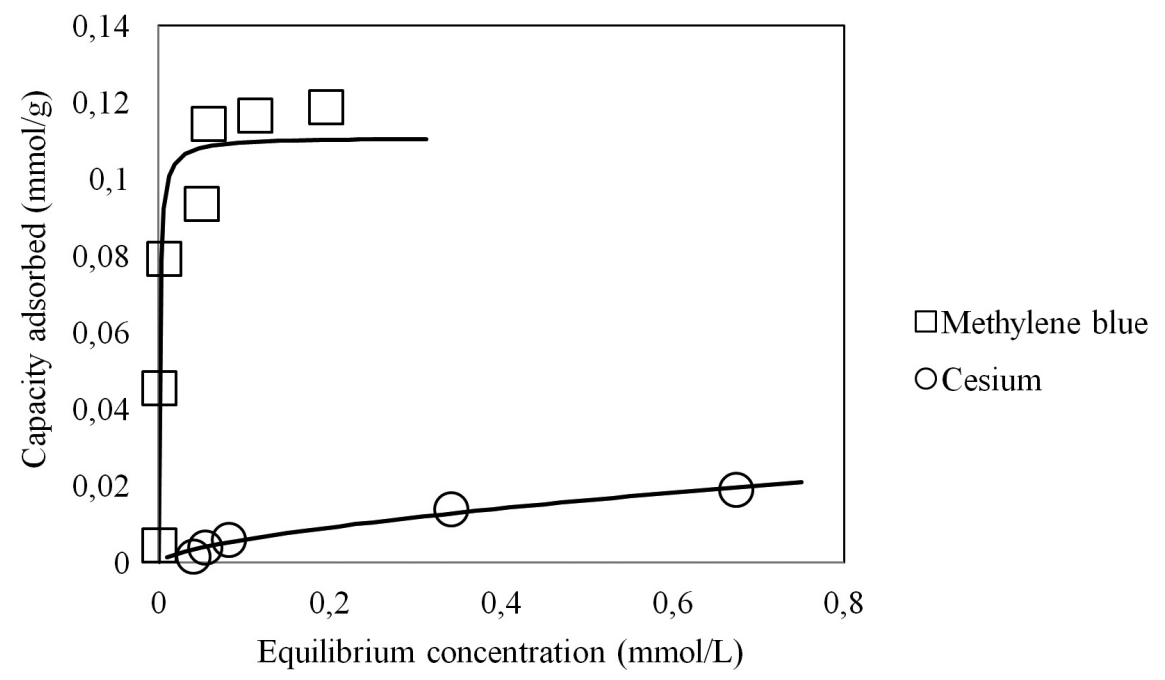

Fig. 7. Equilibrium adsorption of $\mathrm{MB}^{+}$and $\mathrm{Cs}^{+}$by $\mathrm{Ox}-\mathrm{RC}$ (Lines for $\mathrm{MB}^{+}$and $\mathrm{Cs}^{+}$were predicted by Langmuir and Freundlich models, respectively).

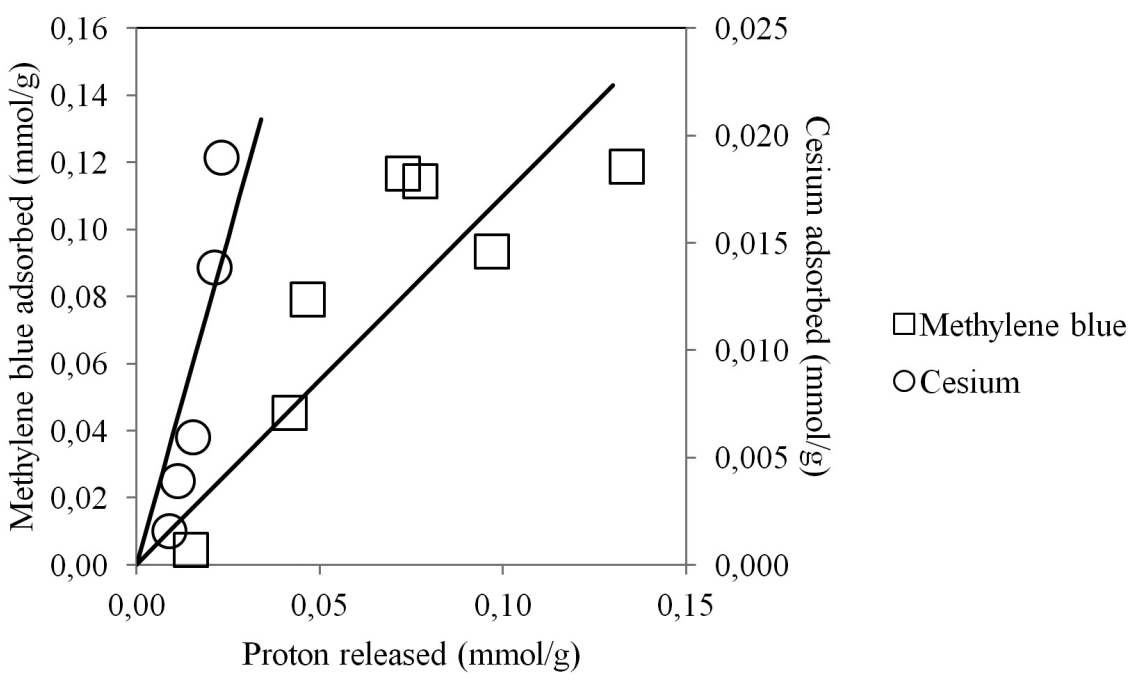

Fig. 8. Relationship between protons released and pollutants adsorbed. 
For one mole of $\mathrm{MB}^{+}$adsorbed, about one mole of equivalent protons is released, while nearly 1.6 moles of protons are required for one mole of $\mathrm{Cs}^{+}$. This pattern signifies the selective adsorption of $\mathrm{MB}^{+}$over that of $\mathrm{Cs}^{+}$by $\mathrm{Ox}-\mathrm{RC}$. Cesium is a monovalent cation that can be easily solvated (surrounded) by dipole (water) molecules. In water, $\mathrm{CS}^{+}$exerts an influence of nearly ten water molecules through linkages with partial negative charge near the oxygen atoms. The formation of solvation shells decreases the charge density, thus decreasing the propensity of $\mathrm{Cs}^{+}$adsorption via ion-exchange.

\section{Conclusion}

Resorcinol-formaldehyde carbon gels were synthesized, characterized and tested for the removal of some pollutants. The $\mathrm{HNO}_{3}$-treated carbon gel (Ox-RC) displayed a lower removal of $\mathrm{MB}^{+}$ compared to the untreated one due to the protonated surface. Despite having a strong adsorption intensity at low equilibrium concentration, both carbon gels exhibit a poor rate constant in which the equilibrium of $\mathrm{MB}^{+}$adsorption was attained only after three days. Adsorbent with slow adsorption rate may not be appropriate for continuous adsorption process. The oxidized carbon gel displays a noticeable removal of $\mathrm{Cs}^{+}$. This highlights the positive effect of surface oxidation to capture certain pollutants. The adsorption of $\mathrm{MB}^{+}$could be associated with the mesoporous attribute of $\mathrm{RC}$, while the removal mechanism of $\mathrm{MB}^{+}$and $\mathrm{Cs}^{+}$ by $\mathrm{Ox}-\mathrm{RG}$ is presumably ion-exchange.

\section{Conflict of Interest}

No potential conflict of interest relevant to this article was reported.

\section{Acknowledgement}

This work was supported by the Hitachi Global Foundation through the award of Postdoctoral Fellowship (HSR171).

\section{References}

1. Ming-Twang S, Lin-Zhi L, Zaini MAA, Zhi-Yong Q, Pei-Yee AY. Activated carbon for dyes adsorption in aqueous solution. In: Daniels JA, ed. Advances in Environmental Research Vol. 36, Nova Science Publishers, New York, 217 (2015).

2. Masuda T, Ogino I, Mukai SR. Immobilization of magnesium ammonium phosphate crystals within microchannels for efficient ammonia removal. Water Sci Technol, 67, 359 (2013). Doi: 10.2166/ wst.2012.525.

3. Rojas-Cervantes ML. Some strategies to lower the production cost of carbon gels. J Mater Sci, 50, 1017 (2015). Doi: 10.1007/s10853-014-8617-1.

4. Mukai SR. Controlling the morphology of carbon gels. Boletin del Grupo Espanol del Carbon, 26, 8 (2012).

5. Tsuchiya T, Mori T, Iwamura S, Ogino I, Mukai SR. Binderfree synthesis of high-surface-area carbon electrodes via $\mathrm{CO}_{2}$ activation of resorcinolformaldehyde carbon xerogel disks: Analysis of activation process. Carbon, 76, 240 (2014). Doi:10.1016/j.carbon.2014.04.074.

6. Al-Muhtaseb SA, Ritter JA. Preparation and properties of resorcinol-formaldehyde organic and carbon gels. Advanced Materials, 15, 101 (2003). Doi: 10.1002/adma.200390020.

7. El-Hendawy ANA. Influence of $\mathrm{HNO}_{3}$ oxidation on the structure and adsorptive properties of corncobbased activated carbon. Carbon, 41, 713 (2003). Doi:10.1016/S0008-6223(03)00029-0.

8. Sing KSW, Everett DH, Haul RAW, Moscou L, Pierotti RA, Rouquerol J, Siemieniewska T. Reporting physisorption data for gas/solid systems with special reference to the determination of surface area and porosity. Pure \& Appl Chem, 57, 603 (1985).

9. Alias N, Zaini MAA. On the view of dielectric properties in microwave-assisted activated carbon preparation. Asia Pac J Chem Eng, 10, 953(2015). Doi: 10.1002/apj.1927.

10. Zaini MAA, Mohamad N. Activated charcoal for oral medicinal purposes: Is it really activated. J App Pharm Sci, 5, 157 (2015). Doi: 10.7324/JAPS.2015.501028.

11. Zaini MAA, Ngiik TC, Kamaruddin MJ, Setapar SHM, Yunus MAC. Zinc chloride-activated waste carbon powder for decolourization of methylene blue. Jurnal Teknologi (Science \& Technology), 67, 37 (2014). Doi: 10.11113/jt.v67.2731.

12. Chensun S, Amano Y, Machida M, Imazeki F. Adsorption of $\mathrm{Pb}(\mathrm{II})$ from aqueous solution on oxidized activated carbon fibers. Sen'i Gakkaishi, 71, 180 (2015). Doi: 10.2115/fiber.71.180. 